\title{
The Influence of Urban Design Packages on Home Values
}

\author{
Christopher Bitter ${ }^{1}$ \\ University of Washington \\ 424 Gould Hall, Box 355740 \\ Seattle, WA 98105 \\ Andy Krause ${ }^{2}$ \\ University of Melbourne \\ MSD Level 4, Room 446 \\ Parkville, VIC 3010
}

Corresponding Author:

Andy Krause (andy.krause@unimelb.edu.au)

\begin{abstract}
Purpose - The purpose of this study is to examine the impact of neighborhood design templates on residential home values in King County, WA, USA. Previous research examines a number of individual design factors; the research here combines these factors into typologies and tests for the impacts of the composite set of design features.
\end{abstract}

Design/methodology/approach - We analyze over 27,000 home sales with a hedonic price model to measure the impacts across three large, regional submarkets. Neighborhood design categories are developed using a cluster analysis on a set of individual neighborhood attributes.

Findings - The key finding from this research is that the impact of more traditional ("urban") design packages on home values is highly contextual. For the older and denser neighborhoods in the study area, more traditional design results in a significantly positive impact on home values. In the new and more suburban regions of the study area this effect is not found.

Originality/value - Prior work has focused on valuing design attributes individually. We argue that neighborhood design is better conceived of as a 'package', as the value of a given design element may

\footnotetext{
${ }^{1}$ Assistant Professor, Department of Urban Design and Planning / Runstad Center for Real Estate Studies, University of Washington, Seattle. bitter@uw.edu. 424 Gould Hall, Box 355740, Seattle, WA.

${ }^{2}$ Lecturer, Department of Property, University of Melbourne, Parkville, Australia. Andy.krause@unimelb.edu.au
} 
depend on other co-located attributes. This is the first study, to our knowledge, to treat physical neighborhood design variables as a composite whole and to attempt to value their impact on home values as such.

Keywords: Neighborhood Design; Neighborhood Attributes; Cluster Analysis; House Price Impacts; Submarket Delineation

Paper Type: Research paper 


\section{Introduction}

It is now widely recognized that urban physical design elements have important repercussions for resource consumption, health, and the environment (Newman and Kenworthy, 1989; Steemers, 2003; Papas et al., 2007; Ewing et al., 2014). The sprawling, auto-centric postwar suburban design template is regarded by many to be less "sustainable" than the compact, walkable, mixed-use neighborhood designs that prevailed prior to the middle of the twentieth century. Recent decades have witnessed a growing call among New Urbanists and advocates of Traditional Neighborhood Development (TND) to return to more traditional neighborhood design templates in order to combat climate change and other perceived ills associated with post-war suburbs (Duany et al., 2000; Wood et al,. 2010). Within this context, "traditional design" refers to neighborhoods consisting of moderately dense development on small lots, with a mix of land uses and high street connectivity (Khattak and Rodriguez, 2005; Wells and Yang, 2008). These traditional characteristics can also be seen as being more "urban", in direct contrast with the low-density, primarily auto-dependent "suburban" design patterns that have been common in US, UK, Australian and some European cities over the past few decades (Duany et al., 2000).

Density, land use configuration and street layout are three key neighborhood physical design elements (Khattak and Rodriguez, 2005; Boer et al., 2007; Mathews and Turnbull, 2007; Duncan et al., 2010.) Each has important implications pertaining to sustainability. Higher density development decreases infrastructure requirements, reduces the amount of energy consumed by buildings, and makes mass transit more efficient (Owen, 2010). Comingling of complementary land uses reduces required trip distances and grid-like street patterns enhance internal connectivity, making walking to satisfy daily needs a viable option. Thus more traditional neighborhood designs, which combine these elements, can help to reduce energy consumption and greenhouse gas emissions (Kahn, 2000; Leinberger, 2007). 
In turn, physical design elements may influence household utility (Nase et al., 2015). If so, buyers will bid up home prices in neighborhoods with desirable design attributes and this additional utility will be capitalized into home values. Therefore, it is important for urban policy makers to understand how neighborhood design influences value - as this may represent a private cost (or benefit) that must be considered along with the broader social and environmental benefits associated with compact development. It is also important for developers, as, if they are to provide more compact forms of development without public subsidy, it must be financially feasible and generate returns commensurate with conventional suburban-style development.

The results of previous attempts to quantify the effect of the individual neighborhood design attributes on home values have not produced definitive conclusions (Song and Knapp, 2003, 2004; Matthews and Turnbull, 2007). The lack of clarity may stem from the fact that the individual elements may interact with one another in the determination of home prices, as synergies may arise from certain combinations of elements. Considered alone, the value of any given neighborhood design attribute may be ambiguous - it may represent either an amenity or a disamenity - depending on the other co-located design elements. For example, density may be less desirable unless coupled with nearby complimentary land uses and walkable streets. For this reason, we argue that more useful results may be achieved by valuing the total neighborhood design "package" - as opposed to attempting to place a separate value on each of the neighborhood's individual design elements.

The present research takes this approach in order to enhance our understanding of how neighborhood design influences property values. We use cluster analysis to group small residential areas, one square mile in size, in King County, Washington (WA), USA (home to Seattle and many of its suburbs) into seven neighborhood design "packages" based on density, land use, and street layout. We then estimate a set of hedonic property value models to quantify the premiums/discounts attributable to a home's location within one of the seven design packages. To evaluate the extent to which the 
premiums/discounts vary with the broader regional context we estimate separate models for each of the County's three primary and geographically-determined housing submarkets.

Our analysis demonstrates that physical neighborhood design attributes do influence housing prices in King County, WA, and more specifically, that homes situated in traditional design "packages" command price premiums over those in suburban-style settings. We also find that slightly higher densities and greater land use mixing can be desirable even in suburban-style settings, as homes in conventionally-designed suburban neighborhoods, where land uses are mixed to a moderate extent, command modest, but statistically significant, pricing premiums over those in their sprawling counterparts in two of the three submarkets considered.

The remainder of the paper is organized as follows. Section One discusses the pertinent literature, while Section Two provides an overview of the study area and its housing market. Following this, Section 3 discusses the methodology used to classify neighborhoods and describes the attributes of the resulting seven neighborhood design packages. Section Four explains the data and modeling process, while the empirical results are discussed in the following section. The final section of the paper draws conclusions and addresses their implications.

\section{Background and Literature Review}

Urban and land economists have long been interested in how the physical design attributes of urban places influence property values and have employed hedonic property value models to quantify their effect on housing prices. For example, early studies by Li and Brown (1980) and Cao and Cory (1981) demonstrated that non-residential land uses impact property values, but that the relationship is complicated because it is characterized by two opposing effects. Proximity to non-residential land uses may reduce utility and property values due to the negative externalities they generate, such as noise or pollution, or increase value because they reduce travel times to complimentary uses (McMillen and McDonald, 2002; Taleai et al., 2007). During the past fifteen years, interest in this topic has grown 
considerably in response to growing awareness of the environmental costs associated with autocentered suburban development. Much of this work is cast within the framework of the New Urbanism and Traditional Neighborhood Development (TND) movements, which favor neighborhoods with moderate density development on small lots, with a mixed land uses and high street connectivity (Khattak and Rodriguez, 2005; Wells and Yang, 2008). For example, Tu and Eppli (1999 and 2001) evaluated differences in home prices between several New Urbanist communities and the conventionally-designed suburban neighborhoods surrounding them. Both studies found that homes in the New Urbanist neighborhoods achieved higher prices. More recently, Bitter (2014) investigated the impact of subdivision vintage on home prices in Tucson, $A Z$, and found that homes located in subdivisions platted prior to World War II, which embody TND principles, commanded price premiums relative to those in the more auto-centric subdivisions platted after 1950 - those that exemplify the post-war suburban paradigm.

Many other researchers have attempted to quantify the property value impact of specific design attributes. For example, Guttery (2002) found that homes located in subdivisions with rear-alleys, often advocated by New Urbanists, reduced home values in Dallas, Texas. Song and Knapp (2003), included multiple design elements associated with New Urbanism in their hedonic model, and found that some elements - , more evenly distributed land uses, better street connectivity, pedestrian accessibility, and light rail access - had a positive impact on home prices in Washington County, Oregon(USA), while others, such as higher densities and greater proportions of commercial, public, and multifamily land uses resulted in discounts. In a subsequent study, Song and Knapp (2004) showed that proximity to parks and neighborhood commercial uses increased home values, while homes located near multifamily developments sold for lower prices, ceteris paribus. However, when evaluated at the neighborhood scale, homes in mixed use neighborhoods were discounted relative to those where single-family residential uses predominated. Song and Sohn (2007) also used Washington County, Oregon (OR) data 
to demonstrate that greater spatial accessibility to retailing had a positive impact on home prices at modest distances - but the effect diminished at shorter distances.

More recently, Kuethe (2012) found that land use diversity did not impact home values in Milwaukee, WI (USA), but that greater land use fragmentation, which brings residential and nonresidential uses closer to one another, diminished value. In a study on tax assessment values (not sales prices), Gilderbloom et al. (2015) find that premiums for properties with a high (top 33\%) Walkscore value - a proprietary measure of 'walkability' - show a $25 \%$ premium over homes in the bottom $66 \%$ of Walkscore values. Finally, two studies by Xiao and co-authors (2016a, 2016b) examine the impact of accessibility - a product of neighborhood design - on home prices in Cardiff, Wales and Nanjing, China, respectively. In Wales (2016a), their work highlights the differences in impacts to price based on the scaling of the accessibility measures. Using a panel dataset, the Nanjing study (2016b) finds that increases in accessibility lead to price increases, however, localized congestions points can act as disamenties pulling nearby prices down over time. In both cases, the impacts of neighborhood design are contextual with regard to changes in design variables over space and time.

Several additional studies have shown that the premiums attributable to physical design attributes may not be universal, but rather vary with locational context. For example, Song and Quercia (2008) found that better street connectivity and pedestrian access were valued more highly in Washington County, Oregon areas classified as "traditional" and "neotraditional" neighborhoods, but in areas deemed to represent "conventional" suburbs more homogeneous land uses and lower densities exhibited greater desirability. Similarly, in a study set in King County, Washington, Matthews and Turnbull (2007) demonstrated that grid-iron like street networks resulted in price premiums in the pedestrian-oriented neighborhoods of Seattle, but that both grid-like street designs and proximity to retail uses diminished housing prices on the Eastside - an affluent conventional suburban area. 
In sum, the findings of this literature provide ample evidence to suggest that neighborhood design influences property values, but it is difficult to draw clear conclusions or meaningful generalizations from this body of work. The lack of clarity is likely due in part to inconsistent measurement of design attributes across studies, as well as to differences in the scale at which neighborhoods are defined. Moreover, many of these studies included relatively sparse specifications of site, structural, and locational attributes in the modeling process, which is problematic because neighborhood design attributes are likely to be correlated with these structural and location attributes. If this was the case - the resulting estimates for the design variables would be biased. A related issue pertains to the fact that physical design attributes themselves are typically highly correlated, which makes it difficult to precisely disentangle their independent effect on home prices.

We, however, believe that the most important issue is conceptual in nature - in that the value of an individual neighborhood design attribute is likely to depend upon the values of the other colocated design attributes. Some combinations may create synergies - thus the value of the whole may exceed the sum of the values of the individual elements. For example, mixed land uses may be desirable, and density more tolerable, when coupled with walkable street grids. While it is technically possible to incorporate these synergies into the hedonic modeling process through the use of complex interaction terms, this comes with a severe loss of interpretability. Therefore, we argue that greater clarity may be achievable by focusing on valuing neighborhood design "packages" as opposed to the individual design elements of which neighborhoods are comprised.

The present research takes this approach. We are not aware of any prior attempts to directly measure the impact of neighborhood design "packages" on property values. We also pay careful attention to spatial effects in the data by segmenting the models by submarket and employing a spatial econometric estimation technique. 


\section{Study Area Overview}

The study is set in King County, Washington (WA), USA, home to the City of Seattle as well as a number of significant suburban communities such as Bellevue, Federal Way, Kent, and Kirkland. The county is the central component of the Seattle-Tacoma-Bellevue Metropolitan Statistical Area (MSA) and contains approximately $60 \%$ of the MSA's 3.5 million residents. The eastern half of the county is mountainous, public forest land and as a result our analysis focuses specifically on the western, urbanized portion of the county.

The urbanized region in the northern portion of the county is split into halves by Lake Washington. The area to the west of the lake is older and more heavily urbanized than the area to the east, and includes the City of Seattle and several of its northern suburbs (See Figure 1 - Location Map). This area, referred to here as the Seattle submarket, includes the CBD and a large portion of the financial and professional services jobs in the region. The area to the east, known locally as the Eastside, is generally suburban in nature but also includes the edge city of Bellevue and its high-rise CBD. The Eastside, home to Microsoft, has the highest incomes and most expensive housing in the State of Washington. The southern portion of the study area, referred to as the Southside, is intermediate between the two in terms of its level of urbanization. The Southside can be described as a predominantly working-class area, as it encompasses the region's largest concentration of industrial sector employment, including a major Boeing plant, and income and educational attainment levels are substantially lower than those found in the other two submarkets.

\footnotetext{
> INSERT Figure 1 - Location Map $<<$
} 


\section{Neighborhood Classification}

\subsection{Methodology}

We began the empirical analysis by segmenting King County neighborhoods into groups (via a cluster analysis) based on their physical design attributes. The resulting classification scheme is then used as a basis to construct the neighborhood-design type dummy variables that are the focus of the hedonic property value models estimated in the second stage of the analysis. The first step entailed choosing appropriate spatial units of analysis. Prior studies have typically used census tracts or block groups as a surrogate for neighborhoods; however, we chose to work with Public Land Survey (PLS) sections instead, as they offer several key advantages. First, census boundaries are drawn to encapsulate a roughly equal number of housing units. This results in spatial units that vary widely in size, as suburban tracts must necessarily be larger than urban tracts where housing densities are higher. This is problematic, because all else equal, small areas are likely to be more homogenous than large areas, causing the extent of land use mixing and diversity to be overstated in suburban areas. PLS sections, on the other hand, are always approximately one square mile in size. Spatial units of this size are also appealing because they approximate a "walking" neighborhood. Finally, PLS sections represent a key organizational unit of the built environment, as major arterials, which often define neighborhood boundaries, are commonly laid out along the boundaries between sections. The main tradeoff of using PLS sections is that the grid is arbitrarily laid over the spatial extent of the study area regardless of topography and political boundaries, and as such, may at times split functional neighborhood units.

Our study area initially included all PLS sections with centroids lying within the King County portion of the Census designated Seattle Urbanized Area. This eliminates PLS sections that are primarily rural in nature. Due to the prevalence of major water bodies in the county, we found that many sections bordering Puget Sound and major inland lakes encompassed land areas much smaller than one square mile. In cases where the total land area was less than 0.5 sq. miles, we combined the PLS section 
with an immediately adjacent section. This modification affected a relatively small proportion of the sections, but does result in some spatial units as small as 0.5 sq. miles, and others as large as 1.5 sq. miles. The total number of neighborhood units available for classification was 469 . Because the paper focuses on single-family properties, eliminated sections that were less than $50 \%$ developed, contained fewer than 100 single family housing units, and those where less than $20 \%$ of the land was devoted to single family homes. In addition, we eliminated sections that represented special-purpose districts such as industrial/port facilities and dense central business districts ${ }^{1}$, as many of these sections were found to be outliers in terms of their design characteristics. A total of 105 sections were eliminated, leaving 364 to be included in the cluster analysis.

The next stage in the classification process involved constructing a variety of physical design variables for each section, including multiple measures of density, street design, and land use. The underlying data comes from the King County Assessor's property data base as well as a variety of other spatially referenced data sources available through the county. Based on the results of an exploratory analysis, we chose to enter six attributes into the cluster analysis. While some papers have used a larger set of indicators to classify neighborhoods (Song and Knapp, 2007), the six chosen variables adequately summarized the larger set of indicators, captured the three major neighborhood physical design principles and produced results that were more readily interpretable. ${ }^{2}$ Brief descriptions of the physical design variables, as well as descriptive statistics, are shown in Table 1. More detailed interpretations and methods of computation are presented in Appendix A.

Although each variable captures a unique aspect of neighborhood design, as Table 2 illustrates, there are strong correlations between several. This highlights one of the advantages of our "package" based approach; it would be difficult to fully disentangle the unique contribution to value of each design attribute if the variables were entered individually into the regression model due to the extent of the collinearity. 


\section{> INSERT Table $1<<$}

\section{> INSERT Table $2<<$}

Next, we standardized the raw values of the six design variables to ensure that each design attribute received equal weight in the classification system. We then used a k-means cluster analysis to group the 364 neighborhood units into one of seven neighborhood design "packages." The K-means clustering algorithm requires the number of groups to be selected a-priori. After analyzing results from a controlled set of different groupings we chose a seven cluster solution because the typology it produced was conceptually appealing (neighborhoods fit into an 'urban' to 'suburban' continuum), was consistent with our knowledge of the study area, and resulted in groups large enough to produce meaningful regression results. Therefore, we view the cluster analysis as an organizational tool to segment the neighborhood units into meaningful groups for further analysis, as opposed to a method of establishing a definitive set of distinct neighborhood design types.

\subsection{Neighborhood Descriptions}

A summary of the design attributes associated with each of the seven neighborhood design packages is provided in Table 3 and individual neighborhood assignments are mapped in Figure 2 - Neighborhood Classifications. Three of the package types incorporate design elements that reflect more traditional, or urban, design principles, three are comprised of attributes commonly associated with suburban design principles, and one has attributes that are intermediate between these two broad categories. In the list below, we give these packages a corresponding number $(1-7)$ indicating the relative level of 'urbanness' with 1 being the most urban (Total count of PLS sections in each category in parentheses).

- 1. Mixed Urban (6): High residential and commercial density, diverse land use, grid-like streets

- 2. Traditional Urban (12): High residential density, less commercial uses, grid like streets 
- 3. Quasi-Urban (24): Moderate residential density, less grid-like streets

- 4. Transitional (37): Low to moderate density, mixed street types, occasional commercial land uses

- 5. Mixed Suburb (44): Low density residential and commercial, usually located near highways, fractured street network, high traffic volume

- 6. Conventional Suburb (109): Primarily low density residential with occasional multifamily uses, somewhat grid-like streets

- 7. Sprawl Suburb (132): Very low residential density, large lots, curvilinear streets and cul-de-sacs

\section{> INSERT Table $3 \ll$ \\ > INSERT Figure 2 - Neighborhood Classifications $<<$}

\section{Hedonic Price Analysis: Data and Methods}

The hedonic price model approach has been widely used to estimate the value of housing and locational attributes. The theoretical context for its application to housing markets was pioneered by Rosen (1974) and rests on the premise that a home can be considered to be a bundle of distinct attributes, and that the implicit price of a given attribute can be recovered by observing how sale prices vary between homes with differing quantities of the attribute, holding the quantities of other attributes constant. We use this approach to estimate the implicit prices associated with the neighborhood design packages explained above. In this section, we explain the data, model, and estimation methods in detail.

\subsection{Data}

Individual home sales within the study area during the period from January 1, 2010 to December 31, 2012 serve as the unit of observation. The transaction data along with information on property 
characteristics and Geographic Information Systems (GIS) parcel layer files were obtained from the King County Assessor. In terms of property characteristics, we collected year-end panel data for all properties within King County for 2010, 2011 and 2012. To aid in the data preparation and validation process, the King County Assessor supplies three fields that provide information regarding the type and purpose of the sale. These fields include information on the instrument used in the transfer of the real property interest, the reason for the sale (if not a basic market transaction) and a list of assessor-defined warnings regarding the sale ${ }^{3}$. Based on these three fields, we identified and excluded non-arm's length sales, foreclosure sales, sales involving large amounts of personal property and other transactions types not likely to be indicative of market value.

Next, we attached land and structural characteristics to each sale using the unique parcel identification number (PIN). The attached characteristics are based on King County Assessor's information from the end of the year that the property sold. After attaching the property information, we culled transactions not involving the sale of single-family dwellings. Next we removed sales with suspect data points, such as those indicating an incomplete structure, homes with more than one building site and sales with questionable property characteristics information such as homes more than five stories tall or with more than 20 bedrooms. Very few sales were eliminated in this secondary cleaning process, suggesting that the Assessor's property data is relatively clean.

King County is home to many luxury homes, especially along the region's many waterfront areas. To limit the impact of these atypical properties on our models' results we removed all waterfront homes, those with more than 3,500 square feet of finished living space, properties sited on lots of greater than two acres ${ }^{4}$ and homes with an Assessor's structural quality ratings greater than 10 (a score of 7 represents average structural quality) from the data set. At the other end of the quality spectrum, we removed sales with an Assessors' structural quality grade of less than 6, the lowest grade meeting current building codes. 
Even with these filters, a number of suspect sales transactions remained. We employed two additional criteria to remove these observations. First, we calculated a sales price to assessed value ratio for each property. The assessed value represents the value on which the property is taxed, and while these values do not perfectly represent market value, assessed values are carefully determined by the local municipalities. Therefore, large deviations between the assessed value and the sales price do offer an indication that the sale may not be a typical arms' length transaction. We examined the price to assessed value ratios and filtered out transactions with extreme ratios. Second, we constructed a submarket-specific filter that removed transactions with prices that represented extreme outliers ${ }^{5}$. Our final data set includes 27,389 valid home sale observations.

Next we added to the sales the local school district test scores, demographic data at the census tract level, neighborhood design attributes, distance to various amenities and disamenities such as major water bodies and freeways. We also created and added a gravity-model based accessibility index using data on street network travel times and local employment estimates obtained through the Puget Sound Regional Council. Finally, we attributed each sale observation with one of the seven neighborhood design package designations.

\subsection{Model Specification / Estimation Methods}

We use a hedonic property value model to estimate the impact of neighborhood design on house prices. Within this context, it is particularly important to control for site, structural, and locational characteristics, as they are correlated with neighborhood design. ${ }^{6}$ In recognition, we include a more extensive set of explanatory variables than was found in previous studies of this nature. These include employment accessibility and interaction terms between age and vintage to control for effect of design features shared by homes built during a given era (Coulson and McMillen, 2008). Descriptions and descriptive statistics (by submarket) for the full set of explanatory variables are shown in Table 4. 


\section{$<<$ Insert Table 4 >>}

As explained earlier, we treat neighborhood design as a package good. Therefore, we exclude any locational attributes from our model specification that were used in the creation of the design packages or are otherwise a product of neighborhood design. Thus, the impacts of these attributes will be expressed in the coefficients of the neighborhood design package variables.

Our models are specified using a semi-log functional form:

$$
\operatorname{Ln} P=\alpha+\beta_{i} S_{i}+\pi_{i} P_{i}+\delta_{i} Y_{i}+\gamma_{i} L_{i}+\lambda_{i} N_{i}+\varepsilon
$$

where $\mathrm{P}$ is the observed home sale price, $\mathrm{S}_{\mathrm{i}}$ is a vector of property structural characteristics, $\mathrm{P}_{\mathrm{i}}$ is a set of parcel (lot) characteristics, $Y_{i}$ is set of quarterly dummy variables denoting quarter of sale, $L_{i}$ is a set of locational characteristics and $\mathrm{N}_{\mathrm{i}}$ are the six neighborhood type variables (the Sprawling Suburban neighborhood category is withheld from the analysis and represents the control group). Although there is no clear consensus as to the correct functional form in hedonic property value models, the semi-log specification was chosen because it has been widely used in the literature, is conceptually appealing as the coefficient estimates represent the approximate percentage change in price attributable to a one unit change in the variable, and it has performed reasonably well in specification comparisons (Cropper et al., 1988).

Given the size of King County, its complex physical geography, and the substantial social and economic differences that exist between the northwestern, northeastern, and southern portions, attribute prices are almost certain to vary across the study area. Therefore, we segmented the study area into its three primary submarkets using multiple listing service (MLS) market area boundaries as a basis. We refer to these as the Seattle, Eastside, and Southside submarkets. To formally determine whether segmentation is warranted, we estimated preliminary models and applied a Chow Test to test for structural differences. The result (chi-squared statistic of 113.32 on 55 and 27,334 degrees of 
freedom $^{7}$ ) confirmed that substantial differences in attribute pricing exist between these submarkets. Based on this result, we estimate separate hedonic models for each submarket. This accomplishes two important objectives. First, it reduces the potential for bias due to spatial heterogeneity; second, it enables us to ascertain the extent to which neighborhood design valuations vary across submarkets.

We first estimated Equation 1 using ordinary least squares (OLS) regression for each of the three submarkets. Due to difficulties in correctly accounting for all spatial attributes that influence price, spatial autocorrelation is common in hedonic models. To combat this, we then calculated Moran's I statistics for each set of residuals. This statistic first requires a spatial weights matrix to be specified. Despite growing interest in this topic within the housing literature, there is still no generally accepted method for choosing the correct form of this matrix. Because the spatial effects themselves are not of direct interest in this study, but rather are considered to represent a nuisance, we chose a relatively simple contiguity-based matrix consisting of each observation's 10 nearest neighbors, weighted by inverse distance, which have been relatively common choices in the literature ${ }^{8}$. As we expected, the Moran's I statistics, shown in Table 5, indicated statistically significant levels of spatial autocorrelation in each of the three submarket models.

\section{> Insert Table $5<<$}

It is important to correct for spatial dependence in order to reduce the potential for bias in the coefficient estimates and their standard errors. In order to do so, it was first necessary to determine the precise form of the spatial dependence in our data. This was accomplished by running LaGrange Multiplier (LM) tests on all three OLS models (Anselin, 1988). The LM statistics overwhelming indicate that spatial dependence in the error terms is the dominant form in each of the three of models (Table 4). Given this result, the spatial error model (SEM) is most appropriate. The only change to the model specification shown in Equation 1 involves the error term: 


$$
\begin{aligned}
\operatorname{Ln} P & =\alpha+\beta_{i} S_{i}+\pi_{i} P_{i}+\delta_{i} Y_{i}+\gamma_{i} L_{i}+\lambda_{i} N_{i}+\mu \\
\mu & =\eta W \mu+\varepsilon
\end{aligned}
$$

where $\mu$ is a disturbance term that is assumed to follow a spatial autoregressive process, $\boldsymbol{\eta}$ is the spatial parameter to be estimated, and $\mathrm{W}$ is the spatial weights matrix that determines which observations are considered in the computation and how they are weighted. This specification greatly reduces spatial autocorrelation in the residuals of all three spatial error models as evidenced by the Moran's I statistics shown in Table $5 .^{9}$

\section{Regression Results}

Summary statistics for the hedonic models are presented in Table 6. The pseudo r-squareds exceed 0.8, demonstrating strong explanatory power, and the standard errors range from 0.12 to 0.16 , indicating reasonable predictive accuracy. The lambda coefficients range from a low of 0.256 in the Southside model to a high of 0.435 in the Eastside model. These relatively high lambda values coupled with significant Wald statistics and elimination of spatial autocorrelation (Table 5) confirm the superiority of the spatial error models over the aspatial OLS specifications.

\section{>> Insert Table $6<<$}

The coefficient estimates for the three hedonic models are shown in Table $7^{10}$. Given the semilog specification employed, the estimates can be interpreted as the approximate percentage change in price associated with a one unit change in the variable. With few exceptions, the control variables are statistically significant, have the anticipated signs, and are of plausible magnitudes. There are, however, notable differences in attribute prices across the three submarkets. For example, older homes are found to be more desirable in Seattle than in the other submarkets, views and high neighborhood 
incomes command greater price premiums on the Southside, and employment accessibility is more highly prized on the Eastside.

\section{>> Insert Table $7<<$}

More interestingly, the regression results indicate that neighborhood design is an important determinant of home prices in King County, WA, as the inclusion of the neighborhood design package variables improves the standard errors and AIC figures in each of the three models relative to models estimated without them ${ }^{11}$. The coefficient estimates for the design variables are statistically significant at the 0.05 level or better in five of thirteen instances. The raw regression coefficients can be interpreted as the approximate percentage difference in price between homes in a given neighborhood design type relative to those in Sprawling Suburban neighborhoods, the control category. The exact percentage differences are given and depicted graphically in Figure $3^{12}$.

\section{> Insert Figure 3 - Price Premiums $<<$}

The Seattle submarket contains the greatest diversity in neighborhood design attributes as all seven design packages are represented. Our hedonic model results demonstrate a clear preference for urban-style neighborhood design packages in this submarket as evidenced by the positive and statistically significant coefficient estimates for all three "urban" package types. Homes located in Mixed Urban neighborhoods are highly sought after and command a premium of nearly $15 \%$ relative to those found Sprawling Suburban neighborhoods homes in Traditional and Quasi Urban neighborhoods also achieve substantial price premiums of $6.4 \%$ and $6.8 \%$ respectively. The nearly equal estimates for these two design packages suggest that higher residential density is not more desirable unless combined with the strong commercial space components and highly mixed land uses found in Mixed Urban neighborhoods. Our results also indicate that Sprawling Suburban neighborhoods have are less 
preferable when compared to Transitional, Mixed Suburban and Conventional Suburban neighborhoods - although the latter estimate is not statistically significant. Thus, the results of the Seattle Submarket demonstrate a nearly perfect progression in pricing across the urban (1) to suburban (7) spectrum.

We find a roughly similar ordering of preferences in the more suburbanized Southside, although Mixed and Traditional Urban neighborhoods are absent in this submarket. Overall, none of the coefficients for the design packages show statistical significance in this submarket. Additionally, inclusion of the design package variables results in less improvement to the model in this submarket, which suggests that home buyers in the Southside place less distinction on physical aspects of neighborhood design.

The Eastside submarket has the least variability in neighborhood design - only four of the seven design packages are found here - and only one section has urban-like design features. The lone Quasi Urban neighborhood encompasses the City of Kirkland's historic downtown. Homes in this neighborhood command a substantial and statistically significant premium of $17.2 \%$ relative to those in Sprawling Suburban Neighborhoods. The outsized premium may reflect the scarcity of opportunities for urban-style living on the Eastside, but idiosyncratic features associated with this unique neighborhood may also play a role as well. In contrast to the Seattle submarket, our results do not indicate that higher densities and greater mixing of land uses contribute to value in suburban-style design settings in the affluent Eastside submarket, as there is almost no difference in pricing between homes in Sprawling and Conventional Suburban neighborhoods, while those in Mixed Suburban neighborhoods are discounted by nearly $2 \%$.

\section{Conclusions}

The results of our analysis suggest that the influence of physical design on property values is highly contextual. We find that within the dense, urban Seattle submarket the value of more desirable 
neighborhood design "packages" was readily capitalized into single family home prices. In the more suburban Southside and Eastside submarkets the premiums for more traditional design packages were much smaller and, often, non-existent. The premiums for urban neighborhoods in the Seattle submarket, where they are most common, are both statistically significant and economically meaningful: they range from approximately $5 \%$ to $15 \%$. Moreover, the even greater premium for the lone urban-style neighborhood in the affluent Eastside Submarket suggests that a market may exist for neighborhoods designed with New Urbanist or TND principals even in suburban settings.

Our results also support the contention that the values of individual design attributes are dependent upon the other attributes with which they are packaged. For example, we found that mixed and diverse land use configurations are more desirable when combined with density and grid-like streets found in Mixed Urban neighborhoods than when packaged with the sparse and disconnected street networks found in Mixed Suburban neighborhoods. This suggests that the negative externalities associated with proximity to non-residential uses may offset the accessibility benefit in areas where internal connectivity, and thus the potential for walking, is limited by weak street grids. The specific premiums for neighborhood design packages found in this study clearly cannot be generalized to other urban areas and regions, but our analysis does have several more general policy and market implications. Most importantly, policy makers and developers should focus on creating neighborhoods that combine design elements in a synergistic manner in order to encourage more sustainable land use patterns. For example, attempts to inject density and mixed uses into existing neighborhoods are likely to be more successful in areas with strong street grids than in those where the streets are less well connected. Similarly, improvements to the street grid should be a priority when attempting to retrofit suburban commercial districts into higher density, mixed use urban villages. Finally, our results suggest that denser residential development at the urban fringe is likely to be more acceptable when combined with more connective street grids and complimentary land uses. 
There are several limitations inherent in our analysis that could be addressed in future research. First, while the PLS sections used to define neighborhood units have a number of desirable properties, they are laid without respect to political boundaries or physical and topographical barriers, thus, they do not always accurately reflect functional neighborhood units. More precise results may be achieved by designing customized spatial units that incorporate these complexities. Second, we only considered the impact of neighborhood design on the value of single-family homes (including townhomes). A more nuanced and complete picture of the connection between physical neighborhood design attributes and property values could be gleaned by incorporating multifamily properties into the analysis as well.

Finally the existence and precise nature of synergies between different design elements could be more fully explored in future work using an interacted-variables approach. 


\section{Appendix A: Neighborhood Design Variable Descriptions}

\section{Residential Density (RESDENS)}

This variable measures the density of housing units within in each section, and is computed by summing the total number of housing units (including both single-family and multi-family dwellings) in each PLS section and dividing by the total land area. Residential densities range from a minimum of 112 units per square mile to a maximum of $7,529$.

\section{Commercial Density (COMDENS)}

Commercial density is calculated by summing the amount of commercial building square footage, including office, retail, hotel, and service uses, within a section and dividing by land area. The greater the commercial density, the more likely that job opportunities and complimentary uses a will be found within the neighborhood. Commercial densities range from a high of 3.6 million square feet to a low of zero.

Land use mix (LUMIX)

Land use mix is an entropy measure commonly used in the literature (Song and Knaap, 2003; Duncan et al., 2010) and measures the extent to which uses in a neighborhood are evenly distributed across five broad land use categories. It is calculated as:

$$
k\left(p_{k} \ln \left(p_{k}\right)\right) / \ln (N)
$$

Where $k$ is the land use category, $p$ is the percentage of land area within each section devoted a given use and $N$ is the total number of categories being considered (five in this case). The land use categories are: 1) Single Family Residential; 2) Multiple Family Residential (including townhomes, lodging and group quarters); 3) Office and Industrial; 4) Services, including retail and public; and 5) Recreational and 
Institutional. LUMIX scores can potentially range from a minimum of 0 (a single use neighborhood) to a maximum of 1 (an exact evenly proportioned neighborhood).

Land use diversity (LUDIV)

This variable measures the diversity of land uses found in each section and is calculated by counting the number of 34 land use sub-types represented within the section (with multiple sub-uses drawn from each of the five primary land use categories used to calculate land use mix). The variable ranges from a minimum score of two to a maximum of 32. This is a distinctly different concept from land use mix, as a neighborhood containing a large single-family home subdivision, several large garden apartment complexes, an office park, and a large public park would receive a high score for land use mix - but a low score on land use diversity, as only a small number of use sub-types are represented.

\section{Street Grid Score (GRIDSCORE)}

GRIDSCORE identifies neighborhoods with Euclidean-like street grids. It is calculated by dividing the count of four-way intersections by the total number of intersections (include two-way, three-way, and those that connect five or more streets) within each section. Neighborhoods with grid-like streets are generally considered to have better internal connectivity and be more walkable than those characterized by curvilinear street patterns and cul-de-sacs. GRIDSCORE ranges from 0 to .69 .

Intersection Density (INTDEN)

Intersection density is calculated by dividing the number of intersections within a section connecting four or more streets by the developable land area within the section. A greater density of intersections within a neighborhood is also thought to enhance connectivity, as it implies smaller block and reduces required travel distances to other sites within the neighborhood, enhancing walkability. Intersection density varies widely within the study area and ranges from zero to 208 per square mile. 


\section{References}

Anselin, L. (1988). Spatial Econometrics: Methods and Models. Dordrecht: Kluwer Academic Publishers.

Bitter, C. (2014). "Subdivision Vintage and Housing Prices: Do Home Buyers Value Traditional Development?” Urban Studies, 51(5):1038-1056.

Boer, R., Zheng, Y., Overton, A., Ridgeway, G. and Cohen, D. (2007). Neighborhood design and walking trips in ten US metropolitan areas." American Journal of Preventive Medicine, 32(4): 298-304.

Cao, T. and Cory, D. (1981). "Mixed Land Use, Land-Use Externalities, and Residential Property Values: A Reevaluation." Annals of Regional Science 16: 1-24.

Coulson, E. and McMillen, D. (2008). "Estimating Time, Age and Vintage Effects in Housing Prices," Journal of Housing Economics 17: 138-151.

Cropper, M., Deck, L. and McConnell, K. (1988). "On the Choice of Functional Form for Hedonic Price Functions," Review of Economics and Statistics 70(4): 668-675.

Duncan, M., Winkler, E., Sugiyama, T., Cerin, E., duToit, L, Leslie, E. and Owen, N. (2010).

"Relationships of Land Use Mix with Walking for Transport: Do Land Uses and Geographical Scale Matter?" Journal of Urban Health: Bulletin of the New York Academy of Medicine 87(5): 782-795.

Leslie, E. and Owen, N. (2010). "Relationships of Land Use Mix with Walking for Transport: Do Land Uses and Geographical Scale Matter?" Journal of Urban Health: Bulletin of the New York Academy of Medicine 87(5): 782-795.

Duany, A., Plater-Zyberk, E. and Speck, J. (2000). Suburban Nation: The Rise of Sprawl and the Decline of the American Dream. New York: North Point Press.

Ewing, R., Meaking, G., Hamidi, S. and Nelson, A. (2014). "Relationship between urban sprawl and physical activity, obesity, and morbidity--Update and refinement." Health \& Place, 26:118-126.

Gilderbloom, J., Riggs, W., and Meares, W. (2015) "Does walkability matter? An examination of walkability's impact on housing values, foreclosures and crime." Cities, 42: 13-24.

Guttery, R. (2002). "The Effects of Subdivision Design on Housing Values: The Case of Alleyways." Journal of Planning Education and Research 23(3): 265-272.

Kahn, M. (2000). "The Environmental Impact of Suburbanization," Journal of Policy Analysis and Management 19(4): 569-586.

Kennedy, P (2003). A Guide to Econometrics. MIT Press. Cambridge, MA.

Khattak, A. and Rodriguez, D. (2005) "Travel behavior in neo-traditional neighborhood developments: A case study in USA." Transportation Research Part A: Policy and Practice, 39(6): 481-500. 
Kuethe, T. (2012). "Spatial Fragmentation and the Value of Residential Housing," Land Economics, 88: 16-27.

Leinberger, C. (2007). The Option of New Urbanism: Investing in an American Dream. Washington, DC: Island Press.

Li, M. and Brown, J. (1980). "Micro-neighborhood Externalities and Hedonic Housing Prices. Land Economics 56: 125-41.

Matthews, J. and Turnbull, G. (2007). "Neighborhood Street Layout and Property Value: The Interaction of Accessibility and Land Use Mix." Journal of Real Estate Finance and Economics 35: 111-141.

McMillen, D. and McDonald, J. (2002). "Land values in a newly zoned city." Review of Economics and Statistics. 84(1): 62-72.

Nase, I., Berry, J. and Adair, A. (2015). "Urban design quality and real estate value: in search of a methodological framework." Journal of Urban Design, 20(5): 563-581.

Newman, P. and Kenworthy, J. (1989) "Gasoline consumption and cities: a comparison of US cities with a global survey." Journal of the American Planning Association, 55(1): 24-37.

Owen, D. (2009). “Green Metropolis: Why Living Smaller, Living Closer, and Driving Less Are the Keys to Sustainability" Riverhead Books, New York, 2009.

Papas, M., Alberg, A., Ewing, R., Helzlsouer, K., Tiffany, G., and Klassen, A. (2007). “The built environment and obesity." Epidemiologic Reviews, 29(1): 129-143.

Rosen, S. (1974). "Hedonic Prices and Implicit Markets: Product Differentiation in Pure Markets," Journal of Political Economics 82: 34-55.

Song, Y. and Knaap, G-J. (2003). "New Urbanism and Housing Values: a Disaggregate Assessment," Journal of Urban Economics 54: 218-238.

Song, Y. and Knaap, G-J. (2004). "Measuring the Effects of Mixed Land Uses on Housing Values," Regional Science and Urban Economics 34: 663-680.

Song, Y. and Knaap, G-J. (2007). "Quantitative Classification of Neighbourhoods: The Neighbourhoods of New Single-family Homes in the Portland Metropolitan Area," Journal of Urban Design 12(1): 1-24.

Song, Y. and Sohn, J. (2007). "Valuing Spatial Accessibility to Retailing: A Case Study of the Single Family Housing Market in Hillsboro, Oregon," Journal of Retailing and Consumer Services 14: 279-288.

Song, Y. and Quercia, R. (2008). "How are Neighbourhood Design Features Valued Across Different Neighbourhood Types?" Journal of Housing and the Built Environment 23: 297-316. 
Steemers, K. (2003) "Energy and the city: density, buildings and transport." Energy and Buildings,35(1): 3-14.

Taleai, M., Sarifi, A., Sliuzas, R. and Mesgari, M. (2007) "Evaluating the compatibility of multi-functional and intensive urban land uses." International Journal of Applied Earth Observation and Geoinformation, 9(4): 375-391.

Tu, C. and Eppli, M. (1999). Valuing New Urbanism: The Case of Kentlands," Real Estate Economics 27: 425-451.

Tu, C. and Eppli, M. (2001). "An empirical evaluation of traditional neighborhood development," Real Estate Economics 29(3): 485-501.

Wells, N. and Yang, Y. (2008) "Neighborhood design and walking: a quasi-experimental longitudinal study." American Journal of Preventive Medicine, 34(4): 313-319.

Wood, L., Frank, L. and Giles-Corti, B. (2010) "Sense of community and its relationship with walking and neighborhood design." Social Science \& Medicine, 70(9): 1381-1390.

Xiao, Y., Orford, S. and Webster, C. (2016a). Urban configuration, accessibility, and property prices: a case study of Cardiff, Wales, Environment and Planning B: Planning and Design, 43(1): 108-129.

Xiao, Y., Webster, C. and Orford, S. (2016b) Identifying house price effects of changes in urban street configuration: An empirical study in Nanjing, China." Urban Studies, 53(1), 112-131. 


\section{Tables and Figures}

Figure 1. Location Map

Figure 2. Neighborhood Design Package Assignments

Figure 3. Price Premiums: Relative to Sprawling Suburban Neighborhoods

Table 1. Neighborhood Design Variable Descriptions and Descriptive Statistics

\begin{tabular}{llcccc}
\hline Variable & Description & Min & Max & Mean & STDEV \\
\hline RESDEN & $\begin{array}{l}\text { Residential units per square mile } \\
\text { COMDEN }\end{array}$ & 112 & 7529 & 1698 & 1274 \\
& $\begin{array}{l}\text { Square feet of commercial space per square } \\
\text { mile (000s) }\end{array}$ & 0 & 3583 & 289 & 499 \\
LUMIX & $\begin{array}{l}\text { Entropy-based index measuring the extent } \\
\text { to which land uses are evenly distributed } \\
\text { across five broad use categories }\end{array}$ & 0 & 0.96 & 0.45 & 0.25 \\
LUDIV & $\begin{array}{l}\text { Number of 34 land use sub categories } \\
\text { present in the neighborhood }\end{array}$ & 2.0 & 32.0 & 13.8 & 8.3 \\
GRIDSC & $\begin{array}{l}\text { Ratio of four-way intersections to total } \\
\text { intersections }\end{array}$ & 0 & 0.69 & 0.19 & 0.14 \\
INTDEN & $\begin{array}{l}\text { Number of four-plus way intersections per } \\
\text { square mile }\end{array}$ & 0 & 208.0 & 28.7 & 36.1 \\
\hline
\end{tabular}

Table 2. Pearson Correlation Coefficients

\begin{tabular}{lcccccc}
\hline & RESDEN & COMDEN & LUMIX & LUDIV & GRIDSC & INTDEN \\
\hline RESDEN & 1 & .625 & .547 & .740 & .700 & .825 \\
COMDEN & .625 & 1 & .581 & .641 & .439 & .546 \\
LUMIX & .547 & .581 & 1 & .762 & .318 & .370 \\
LUDIV & .740 & .641 & .762 & 1 & .607 & .634 \\
GRIDSC & .700 & .439 & .318 & .607 & 1 & .867 \\
INTDEN & .825 & .546 & .370 & .634 & .867 & 1 \\
\hline
\end{tabular}


Table 3. Design Attribute Mean Values by Neighborhood Design Package Type

\begin{tabular}{lccccccc}
\hline Cluster Name & $\mathrm{N}$ & RESDEN & COMDEN & LUMIX & LUDIV & GRIDSC & INTDEN \\
\hline Mixed Urban & 6 & 6553 & 2475 & .81 & 27.8 & .50 & 140.4 \\
Traditional Urban & 12 & 4526 & 782 & .65 & 26.9 & .52 & 150.6 \\
Quasi Urban & 24 & 3477 & 784 & .65 & 26.0 & .45 & 83.9 \\
Transitional & 37 & 2267 & 127 & .44 & 17.4 & .34 & 51.0 \\
Mixed Suburb & 44 & 2096 & 844 & .77 & 23.4 & .18 & 25.0 \\
Conventional Suburb & 109 & 1507 & 161 & .54 & 13.6 & .12 & 14.2 \\
Sprawl Suburb & 132 & 763 & 21 & .19 & 5.7 & .12 & 9.6 \\
\hline
\end{tabular}


TABLE 4. Variable Descriptions and Summary Statistics

\begin{tabular}{|c|c|c|c|c|c|c|c|}
\hline Name & Desc & $\begin{array}{c}\text { Eastside } \\
\text { Mean }\end{array}$ & $\begin{array}{c}\text { Eastside } \\
\text { St Dev }\end{array}$ & $\begin{array}{c}\text { Seattle } \\
\text { Mean }\end{array}$ & $\begin{array}{l}\text { Seattle } \\
\text { St Dev }\end{array}$ & $\begin{array}{c}\text { Southside } \\
\text { Mean }\end{array}$ & $\begin{array}{c}\text { Southside } \\
\text { St Dev }\end{array}$ \\
\hline LNPrice & Natural Log of the Sales Price & 13.10 & 0.33 & 12.93 & 0.44 & 12.48 & 0.34 \\
\hline TownHome & Is a townhome? & 0.01 & 0.09 & 0.04 & 0.19 & 0.01 & 0.07 \\
\hline OneStory & Is single story? & 0.48 & 0.50 & 0.56 & 0.50 & 0.47 & 0.50 \\
\hline SFSQ & Square Footage (in 100s) Squared & 575.24 & 285.85 & 352.49 & 252.35 & 437.66 & 253.53 \\
\hline SFABV & Above Ground SqFt (in 100s) & 20.53 & 6.83 & 14.24 & 5.10 & 18.38 & 6.21 \\
\hline SFBaseF & Basement SqFt Finished (in 100s) & 2.65 & 4.21 & 3.40 & 3.98 & 1.67 & 3.29 \\
\hline SFBaseUF & Basement SqFt Unfin. (in 100s) & 0.48 & 1.75 & 2.80 & 3.54 & 0.42 & 1.66 \\
\hline Baths & Number of Bathrooms & 2.30 & 0.53 & 1.78 & 0.71 & 2.17 & 0.58 \\
\hline Bedrooms & Number of Bedrooms & 3.61 & 0.71 & 3.14 & 0.91 & 3.48 & 0.69 \\
\hline BG_6 & Structural Quality = 6 & 0.01 & 0.11 & 0.14 & 0.35 & 0.06 & 0.24 \\
\hline BG_8 & Structural Quality = 8 & 0.40 & 0.49 & 0.26 & 0.44 & 0.33 & 0.47 \\
\hline BG_9 & Structural Quality = 9 & 0.24 & 0.43 & 0.08 & 0.28 & 0.10 & 0.30 \\
\hline BG_10 & Structural Quality = 10 & 0.09 & 0.29 & 0.02 & 0.14 & 0.02 & 0.12 \\
\hline ConBelow & Condition is Below Average & 0.00 & 0.04 & 0.01 & 0.07 & 0.00 & 0.05 \\
\hline ConAbove & Condition is Above Average & 0.29 & 0.46 & 0.30 & 0.46 & 0.27 & 0.44 \\
\hline ConExc & Condition is Excellent & 0.05 & 0.22 & 0.09 & 0.29 & 0.03 & 0.18 \\
\hline Age & Age of Structure & 29.91 & 18.04 & 62.83 & 29.61 & 24.93 & 20.61 \\
\hline PreWar & Structure Built Pre World War II & 0.01 & 0.11 & 0.48 & 0.50 & 0.02 & 0.15 \\
\hline PostWar & Structure Built Post World War II & 0.37 & 0.48 & 0.34 & 0.47 & 0.29 & 0.45 \\
\hline AgePre & Age * PreWar & 0.99 & 9.12 & 41.70 & 44.13 & 1.74 & 11.80 \\
\hline AgePost & Age * PostWar & 17.41 & 23.13 & 19.08 & 26.94 & 13.76 & 22.00 \\
\hline Ren_10 & Renovated in Last 10 Years & 0.01 & 0.11 & 0.03 & 0.17 & 0.01 & 0.08 \\
\hline New & New Home Sale & 0.10 & 0.30 & 0.07 & 0.25 & 0.21 & 0.41 \\
\hline GarSF & Garage Square Foot in (100s) & 5.14 & 2.21 & 2.61 & 2.19 & 4.83 & 2.32 \\
\hline GarSF2 & Garage SqFt Squared (in 100s) & 31.35 & 29.71 & 11.59 & 19.66 & 28.74 & 46.39 \\
\hline FirePIcs & Number of Fireplaces & 1.47 & 0.64 & 1.09 & 0.70 & 1.15 & 0.56 \\
\hline DeckSF & Deck Square Foot (in 100s) & 1.48 & 2.22 & 0.98 & 1.62 & 0.77 & 1.54 \\
\hline PorchExt & Has an Exterior Porch & 0.61 & 0.90 & 0.44 & 0.74 & 0.54 & 0.79 \\
\hline LotSF & Lot SqFt (in 1000s) & 12.12 & 10.14 & 6.26 & 3.95 & 9.72 & 8.49 \\
\hline LotSFSQ & Lot SqFt Squared (in 1000s) & 249.69 & 600.44 & 54.86 & 156.92 & 166.63 & 536.51 \\
\hline ViewScore & View Score (calculated) & 0.64 & 2.69 & 1.37 & 3.97 & 0.43 & 2.19 \\
\hline Score4 & Fourth Grade Test Scores & 24.17 & 2.96 & 20.65 & 5.48 & 19.12 & 4.24 \\
\hline Score10 & Tenth Grade Test Scores & 25.81 & 2.23 & 22.63 & 3.45 & 21.91 & 2.69 \\
\hline Medlnc & Median HH Income (in $\$ 10,000$ s) & 13.00 & 4.16 & 9.56 & 3.23 & 8.48 & 1.84 \\
\hline Blk_Hisp & $\%$ Black or Hispanic & 0.07 & 0.04 & 0.13 & 0.11 & 0.17 & 0.09 \\
\hline Asian & \%Asian & 0.19 & 0.09 & 0.14 & 0.10 & 0.16 & 0.09 \\
\hline Highway & Within 1,000 Feet of Highway & 0.06 & 0.23 & 0.06 & 0.23 & 0.04 & 0.19 \\
\hline Industrial & Z Value of Percent Industrial & -0.19 & 0.68 & -0.07 & 0.76 & -0.14 & 0.77 \\
\hline Water & Within $1 / 8$ Mile of Major Waterbody & 0.03 & 0.16 & 0.04 & 0.19 & 0.01 & 0.11 \\
\hline EmpAcc & Employment Accessibility & 1.09 & 0.41 & 1.83 & 0.68 & 0.82 & 0.26 \\
\hline MixUrban & Urban Mix Neighborhood & 0.00 & 0.00 & 0.06 & 0.23 & 0.00 & 0.00 \\
\hline TradUrban & Urban Traditional Neighborhood & 0.00 & 0.00 & 0.22 & 0.41 & 0.00 & 0.00 \\
\hline QuasiUrban & Quasi-Urban Neighborhood & 0.02 & 0.12 & 0.29 & 0.46 & 0.01 & 0.10 \\
\hline Trans & Transitional Neighborhood & 0.00 & 0.00 & 0.32 & 0.47 & 0.03 & 0.17 \\
\hline MixSub & Suburban Commercial Neighborhood & 0.13 & 0.33 & 0.05 & 0.21 & 0.08 & 0.27 \\
\hline ConSub & Suburban Conventional Neighborhood & 0.40 & 0.49 & 0.04 & 0.18 & 0.60 & 0.49 \\
\hline QuarterlyDummies & Quarterly Dummy Variables & NA & NA & NA & NA & NA & NA \\
\hline AreaDummies & City Dummy Variables & NA & NA & NA & NA & NA & NA \\
\hline
\end{tabular}


Table 5. Spatial Diagnostics

\begin{tabular}{crrrrrr}
\hline Model & Moran's I & Z-value & LM Lag & LM Lag R & LM Error & LM Error R \\
\hline Seattle & 0.24 & 36.18 & 27 & 11 & 1308 & 1292 \\
OLS & -0.02 & -3.31 & & & & \\
SEM & & & & & & \\
Eastside & 0.30 & 36.93 & 24 & 12 & 1361 & 1350 \\
OLS & -0.03 & -3.43 & & & & \\
SEM & & & & & & \\
Southside & 0.16 & 19.63 & 4 & 1 & 384 & \\
OLS & -0.02 & -2.63 & & & & \\
SEM & & & & & & \\
\hline \hline
\end{tabular}

Table 6. Spatial Model Summaries

\begin{tabular}{|c|c|c|c|c|c|}
\hline & St. Error & $\begin{array}{l}\text { Pseudo R- } \\
\text { squared }\end{array}$ & Lambda & Wald Statistic & $\mathbf{N}$ \\
\hline Seattle & 0.162 & 0.860 & 0.374 & 1387 & 12,042 \\
\hline Eastside & 0.117 & 0.874 & 0.435 & 1464 & 8,030 \\
\hline Southside & 0.133 & 0.841 & 0.256 & 347 & 7,317 \\
\hline
\end{tabular}


Table 7. Hedonic Model Results

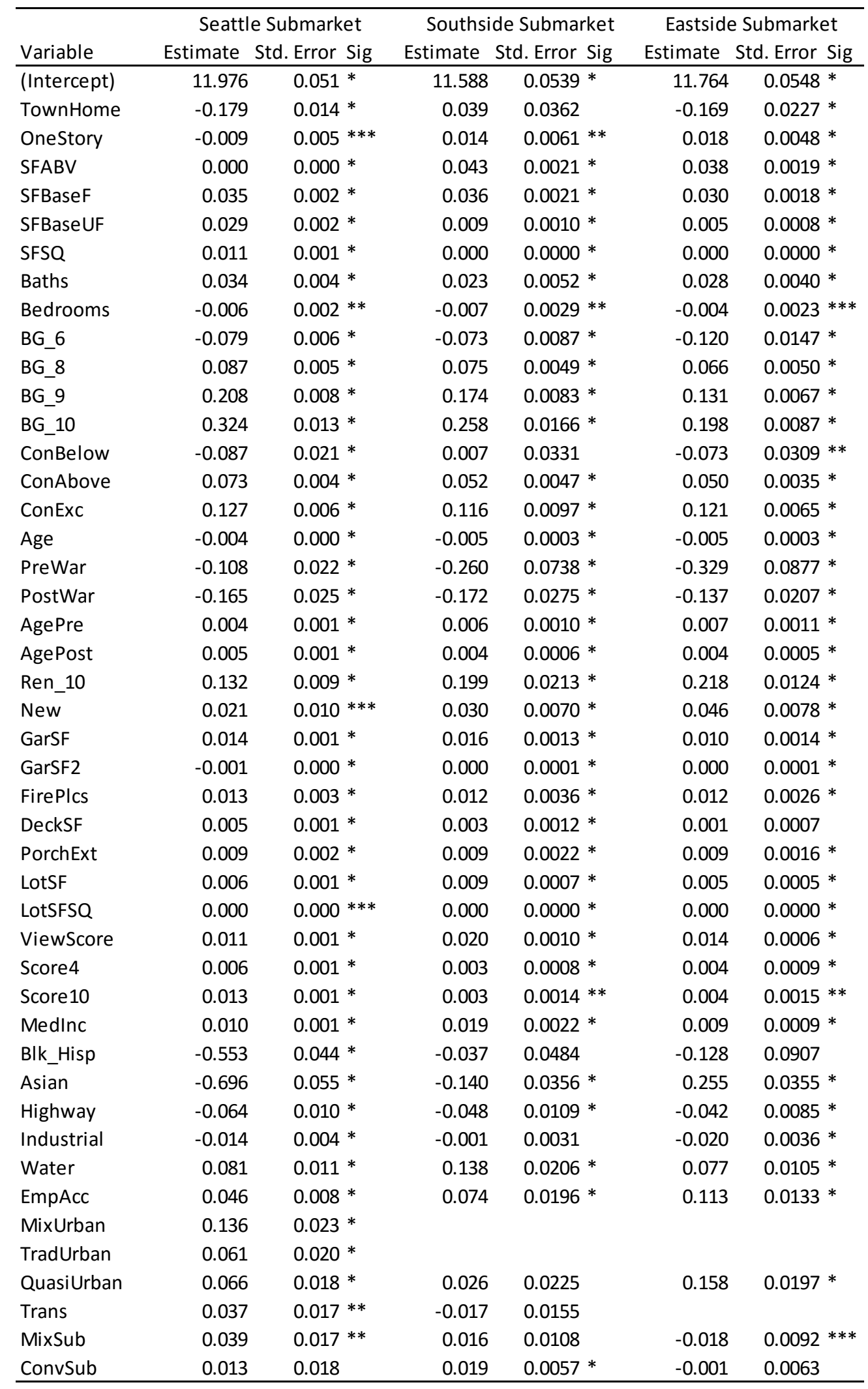

* Signficant at $0.01 ;{ }^{* *}$ Significant at $0.05 ;{ }^{* * *}$ Signficant at 0.10 


\section{Notes}

${ }^{1}$ Defined as a CBD or any other section where the proportion of land devoted to a single non-residential land use category (industrial, office, or institutional) exceeded $50 \%$ of the developed area.

${ }^{2}$ In contrast to prior work, we did not include a variable representing access to mass transit because we don't consider this to be a physical "design" attribute per se. Buses represent the dominant form of public transit in King County and service is provided on existing roads rather than fixed infrastructure, thus the routes and stops are flexible and not permanently embedded into the physical fabric of neighborhoods.

${ }^{3}$ These warnings include codes denoting a multiple-parcel sale, a sale by a relocation agency or a tear-down sale, as examples.

${ }^{4}$ Lots greater than two acres are atypical in the study area, which encompasses the substantially urbanized portion of King County, and often have irregular dimensions. We eliminated 155 records exceeding this threshold because homes with acreage or excess land are likely to be valued differently from those sited on typical building lots.

${ }^{5}$ Approximately 250 records, representing less than $1 \%$ of the total number of observations, were removed as price outliers.

${ }^{6}$ Based on Variable Inflation Factors (VIFs) calculated for the predictive variables, substantial multicollinearity is present in our models. However, this does not result in biased coefficients, rather it increases the variance of the estimates, and is not deemed problematic so long as the variances of the variables of interest are estimated at an acceptable level of precision (Kennedy, 2003).

${ }^{7}$ A p-value of 0

${ }^{8}$ We also tested several alternative spatial weights matrixes and found the results to be reasonably consistent. The mean and maximum distances to the $10^{\text {th }}$ nearest neighbor in miles are: 0.13 / 1.13 in the Seattle Submarket; 0.18 / 1.11 in the Eastside Submarket; and 0.19 / 1.50 in the Southside Submarket. The maximum distances are within acceptable thresholds for appraisals in low-density suburban areas.

${ }^{9}$ In fact, the spatial autocorrelation becomes slightly negative. This result is likely attributable to using a global spatial weights specification in a situation where there may be spatial heterogeneity in the structure of the spatial dependence in prices.

${ }^{10}$ In order to preserve space, the coefficient estimates for the 11 year-quarter dummy variables have been suppressed.

${ }^{11}$ Models estimated with the original six design variables entered individually demonstrate slightly better AICs and standard errors and hypothesis tests indicate the differences between models are statistically significant, which suggests the design clusters are not capturing all the variability in the underlying design variables.

${ }^{12}$ Calculated using the formula $e^{\beta i}-1$, where $\beta_{i}$ is the relevant coefficient estimate. 


\section{University Library}

\section{- M M N E R VA A gateway to Melbourne's research publications}

Minerva Access is the Institutional Repository of The University of Melbourne

Author/s:

Bitter, C;Krause, A

Title:

The influence of urban design packages on home values

Date:

2017-01-01

Citation:

Bitter, C. \& Krause, A. (2017). The influence of urban design packages on home values.

INTERNATIONAL JOURNAL OF HOUSING MARKETS AND ANALYSIS, 10 (2), pp.184-203. https://doi.org/10.1108/IJHMA-08-2015-0049.

Persistent Link:

http://hdl.handle.net/11343/122181

License:

Unknown 